\title{
P2X7 blockade attenuates mouse liver fibrosis
}

\author{
CHANGSHAN HUANG, WEI YU, HONG CUI, YUNJIAN WANG, \\ LING ZHANG, FENG HAN and TAO HUANG \\ Department of Hepatobiliary Surgery, Henan Provincial Cancer Hospital, \\ Zhengzhou, Henan 450008, P.R. China
}

Received May 23,2013; Accepted October 10, 2013

DOI: $10.3892 / \mathrm{mmr} .2013 .1807$

\begin{abstract}
P2X7 is important in inflammation and tissue injury. The aim of the present study was to investigate the effect of P2X7 inhibition, using a specific inhibitor (A438079) to prevent the development of liver injury and fibrosis in a mouse model of liver fibrosis. The mouse liver fibrosis model was induced by carbon tetrachloride $\left(\mathrm{CCl}_{4}\right)$. Mice received subcutaneous administration of vehicle (saline/olive oil), $\mathrm{CCl}_{4}$ or subcutaneous $\mathrm{CCl}_{4}$ and $\mathrm{A} 438079$. The pro-inflammatory and pro-fibrotic factors were determined by western blot analysis. The biochemistry, histopathology, collagen deposition and nuclear factor- $\kappa \mathrm{B}(\mathrm{NF}-\kappa \mathrm{B})$ activity were also analyzed. Chronic $\mathrm{CCl}_{4}$ treatment resulted in liver injury and collagen accumulation. The expression levels of P2X7, pro-inflammatory and pro-fibrotic mediators, and the activity of NF- $\kappa \mathrm{B}$ were markedly increased. Treatment with A438079 significantly inhibited $\mathrm{CCl}_{4}$-induced $\mathrm{P} 2 \mathrm{X} 7$ expression, and attenuated $\mathrm{CCl}_{4}$-induced liver injury and the inflammatory response. $\mathrm{P} 2 \mathrm{X} 7$ blockade also significantly reduced the formation of collagen in the liver and the expression of $\alpha$-smooth muscle actin and transforming growth factor- $\beta 1$. This study demonstrated that P2X7 inhibition attenuated liver injury and fibrosis in a mouse model. Thus, P2X7 is a potential novel therapeutic target for liver injury and fibrosis.
\end{abstract}

\section{Introduction}

Liver fibrogenesis is often present in various types of chronic liver disease. Hepatic fibrosis, characterized by the excessive generation of extracellular matrix constituents (particularly collagens), is a precursor of cirrhosis (1). The mortality of patients with liver fibrosis is gradually increasing (2) and long-term liver fibrosis contributes to the development of hepatocellular carcinoma, which is a malignancy of global importance that is

Correspondence to: Dr Changshan Huang, Department of Hepatobiliary Surgery, Henan Provincial Cancer Hospital, 127 Dongming Road, Zhengzhou, Henan 450008, P.R. China E-mail: hnhuangcshan@yeah.net

Key words: P2X7, inflammation, liver fibrosis, carbon tetrachloride difficult to treat (3). Although numerous agents have been used in the treatment of hepatic fibrosis, these are rarely effective (4). Therefore, an effective therapy is urgently required.

$\mathrm{P} 2 \mathrm{X} 7$ is a member of the ionotropic purinergic receptor family that is activated by ATP (5). P2X7 activity is demonstrated to be readily detectable in cells of hemopoietic lineage, including monocytes, macrophages, dendritic cells and lymphocytes $(6,7)$. The key involvement of $\mathrm{P} 2 \mathrm{X} 7$ activation in inflammation and interleukin-1 $\beta$ (IL-1 $\beta$ ) maturation has been previously confirmed (8). In addition, during chronic inflammation, P2X7 is significantly upregulated in macrophages $(9,10)$. Studies have demonstrated that the absence or inhibition of $\mathrm{P} 2 \mathrm{X} 7$ is associated with less severe chronic inflammation, indicating that $\mathrm{P} 2 \mathrm{X} 7$ functions as an integral component of an in vivo pro-inflammatory mechanism $(11,12)$. Notably, it has recently been shown that $\mathrm{P} 2 \mathrm{X} 7$ is involved in lung fibrosis by promoting IL-1 $\beta$ maturation (13). However, it remains to be determined whether $\mathrm{P} 2 \mathrm{X} 7$ contributes to hepatic fibrosis. The aim of the present study was to investigate whether specific inhibition of P2X7 attenuated the progression of chronic liver injury and fibrosis in a mouse liver fibrotic model induced by carbon tetrachloride $\left(\mathrm{CCl}_{4}\right)$.

\section{Materials and methods}

Liver fibrosis induction and treatment. Procedures were reviewed and approved by the Ethics Committee of the Henan Provincial Cancer Hospital. Male C57BL/6 mice (age, 6 weeks) from Henan Provincial Animal Center were used in this study. Mice were maintained under specific pathogen-free conditions. Hepatic fibrosis was induced by subcutaneously injecting a 1:1 solution of $\mathrm{CCl}_{4}$ in olive oil (Chemical Agent Company of Shanghai, Shanghai, China). The solution was administered three times a week for four weeks. At the end of the first week, $\mathrm{CCl}_{4}$-injected mice were divided into two groups: $\mathrm{CCl}_{4}$ alone and $\mathrm{CCl}_{4}$ plus $\mathrm{A} 438079$ (subcutaneous infusion) once daily. The usage of $\mathrm{A} 438079$ was based on a previous study (14). In brief, A-438079 was diluted at $3 \mathrm{mg} / \mathrm{ml}$ in vehicle solution (saline). A-438079 (34.2 mg/ $\mathrm{kg}$ ) was then administered subcutaneously to mice every $24 \mathrm{~h}$.

The animals were divided into three groups $(n=12$ per group): i) normal control with vehicle (saline/olive oil) alone administered by subcutaneous injection; ii) $\mathrm{CCl}_{4}$ (dissolved in olive oil) alone, administered by subcutaneous injection; iii) $\mathrm{CCl}_{4}+\mathrm{A} 438079$, administered by subcutaneous injection. 
Histopathological analysis. Mice were sacrificed by carbon dioxide asphyxiation at the end of the fourth week subsequent to the initial injection ( $24 \mathrm{~h}$ following final injection). Blood was collected by cardiac puncture, and serum was obtained by centrifugation of blood at $600 \mathrm{xg}$ for $10 \mathrm{~min}$, and stored at $-20^{\circ} \mathrm{C}$. Liver tissues were fixed in $10 \%$ phosphate-buffered formalin and embedded in paraffin. The paraffin blocks were cut into 4- $\mu \mathrm{m}$ tissue sections. The sections were stained with hematoxylin and eosin. The collagen that had accumulated in the liver sections was stained with $0.1 \%$ Picro-Sirius Red (Polysciences Inc., Warrington, PA, USA) and quantified by an image analyzer (Leica Microsystems Ltd., Buffalo Grove, IL, USA). The percentage area of the total quantity of collagen was determined by the total of the areas of Sirius Red positive stain divided by the reference field multiplied by 100 . The percentage positive area of the central veins was determined by the total of the areas of Sirius Red positive stain in the central veins divided by the reference field multiplied by 100 . The percentage positive of the perihepatic region was calculated by subtracting the percentage positive of total area and the percentage of the central vein.

Determination of serum alanine aminotransferase (ALT) activity. Increased serum ALT level is a common indicator of hepatic injury. The ALT assay was conducted using a commercially available kit according to the manufacturer's instructions (Wako Pure Chemical, Tokyo, Japan).

RNA extraction and reverse transcriptase-polymerase chain reaction (RT-PCR). Total RNA was extracted from liver tissue using TRIzol (Life Technologies, Carlsbad, CA, USA). The preparation of the first-strand cDNA was performed by using the SuperScript ${ }^{\mathrm{TM}}$ First-Strand Synthesis System (Invitrogen Life Technologies, Carlsbad, CA, USA), according to the manufacturer's instructions. The mRNA expression levels of P2X7 were measured by RT-PCR. The primers forward: 5'-GTGCCATTCTGACCAGGGTTGTATAAA-3' and reverse: 5'-GCCACCTCTGTAAAGTTCTCTCCGAT-3' were used for P2X7; and glyceraldehyde 3-phosphate dehydrogenase was amplified as an internal control.

Measurement of tumor necrosis factor- $\alpha$ (TNF- $\alpha), I L-1 \beta$ and $C C L 2$ in the sera. The sera were collected for the measurement of TNF- $\alpha$, IL- $1 \beta$ and CCL2 by enzyme-linked immunosorbent assay (ELISA; R\&D Systems, Minneapolis, MN, USA), according to the manufacturer's instructions.

Western blot analysis. The liver tissues were lysed at $4^{\circ} \mathrm{C}$ in RIPA buffer (Qiagen, Valencia, CA, USA) and extracts were clarified at $12,000 \mathrm{x}$ g for $25 \mathrm{~min}$. Following separation by sodium dodecyl sulfate-polyacrylamide gel electrophoresis, proteins were assessed using the bicinchoninic acid assay protein concentration assay kit (Pierce Biochemicals, Rockford, IL, USA). Aliquots (60-90 $\mu \mathrm{g}$ protein) were electrophoretically separated, transferred to nitrocellulose membranes and incubated overnight with the following specific primary antibodies: anti-TGF- $\beta 1$, 1:2,000, anti- $\alpha$-SMA antibody, 1:1,000; anti-P2X7 antibody, 1:500; anti- $\beta$-tubulin antibody, 1:5,000 (Abcam, Cambridge, MA, USA). Following three washes, primary antibodies were detected with horseradish peroxidase-labeled secondary
A

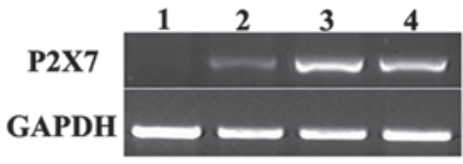

B

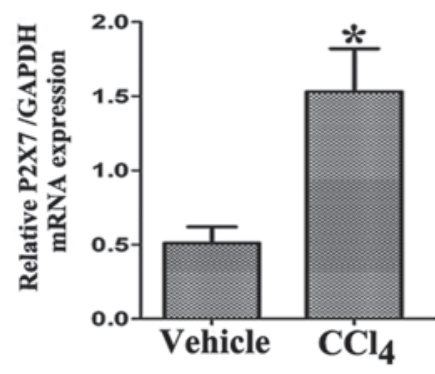

C

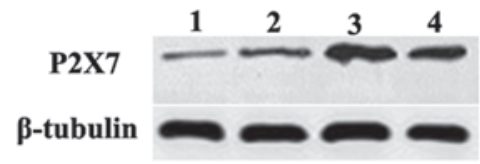

D

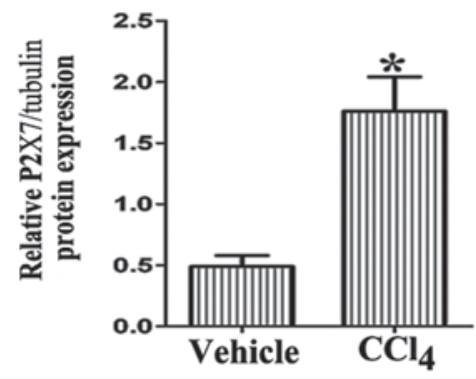

Figure 1. P2X7 expression in livers following carbon tetrachloride $\left(\mathrm{CCl}_{4}\right)$ induction. The mRNA and protein were extracted and subjected to (A and B) reverse transcription-polymerase chain reaction (RT-PCR) analysis and (C and D) western blot analysis. The relative mRNA and protein expression levels were expressed as the ratio of band intensity for $\mathrm{P} 2 \mathrm{X} 7$ relative to that for internal controls, glyceraldehyde 3-phosphate dehydrogenase (GAPDH) or $\beta$-tubulin. Values are expressed as the mean $\pm \mathrm{SD}, \mathrm{n}=12$ mice per group. ${ }^{*} \mathrm{P}<0.01$, compared with vehicle-treated normal control. Lane 1 and 2, vehicle (saline/olive oil)-treated normal mice; lane 3 and 4, $\mathrm{CCl}_{4}$ administered by subcutaneous injection.

antibody (1:5,000; Abcam). The activity of nuclear factor- $\mathrm{\kappa B}$

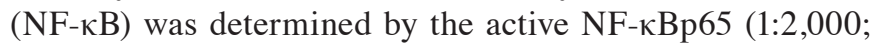
Abcam) using western blot analysis. Histone H3 (1:3,000; Abcam) was used as nuclear internal control. Immunoreactive proteins were visualized with an enhanced chemiluminescence reagent (Amersham Biosciences, Piscataway, NJ, USA) and quantitated by densitometry (GE Healthcare, Little Chalfont, UK).

Statistical analysis. Data from each group are expressed as the mean \pm SD. Statistical comparisons between the groups were conducted using the Kruskal-Wallis test followed by Dunn's post hoc test to compare all the groups. $\mathrm{P}<0.05$ was considered to indicate a statistically significant difference.

\section{Results}

Enhanced $\mathrm{P} 2 \mathrm{X} 7$ expression in $\mathrm{CCl}_{4}$-induced liver fibrosis. The $\mathrm{P} 2 \mathrm{X} 7$ expression in liver tissues from the $\mathrm{CCl}_{4}$-induced liver fibrosis model and from vehicle-treated normal controls was 


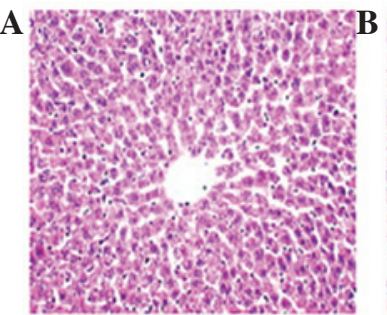

Vehicle

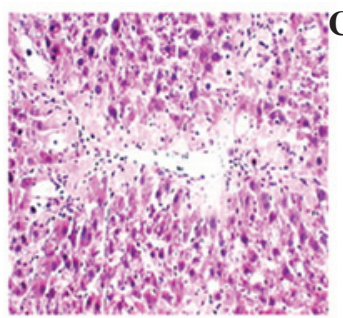

$\mathrm{CC1}_{4}$

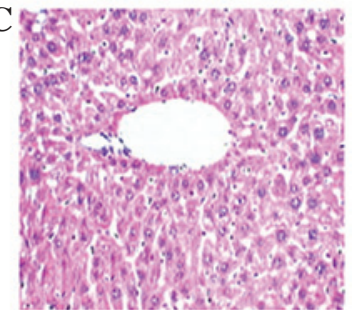

$\mathbf{A 4 3 8 0 7 9}$

$\mathbf{D}$

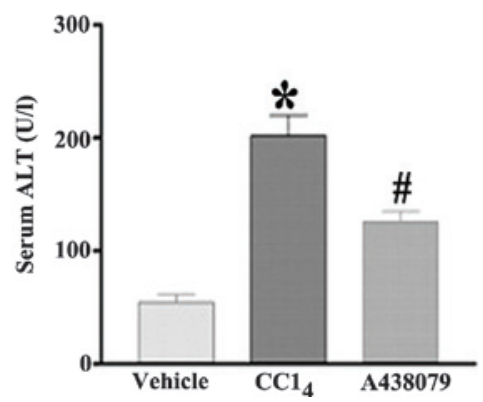

Figure 2. Representative images of hematoxylin and eosin staining. (A) Vehicle-treated normal control, (B) carbon tetrachloride $\left(\mathrm{CCl}_{4}\right)$-treated and (C) $\mathrm{CCl}_{4}+\mathrm{A} 438079$-treated groups. A necrotic area was present in $\mathrm{CCl}_{4}$-treated mice with significantly large quantities of inflammatory cell infiltration surrounding the centrilobular veins. No significant necrosis was observed in the $\mathrm{A} 438079$ and $\mathrm{CCl}_{4}$-treated group. (D) $\mathrm{CCl}_{4}$ treatment resulted in significantly increased serum alanine aminotransferase (ALT) levels. ${ }^{*} \mathrm{P}<0.01$, vs. the vehicle-treated normal control and ${ }^{\#} \mathrm{P}<0.01$, vs. the $\mathrm{CCl} \mathrm{l}_{4}$-treated group ( $\mathrm{n}=10-12$ per group). Magnification, x200.

A

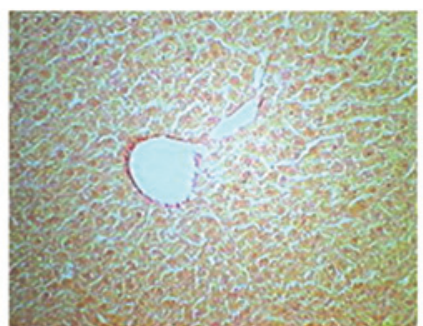

C

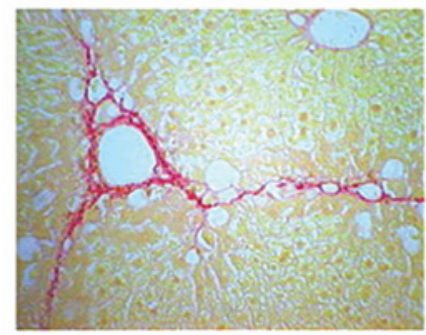

$\mathbf{E}$

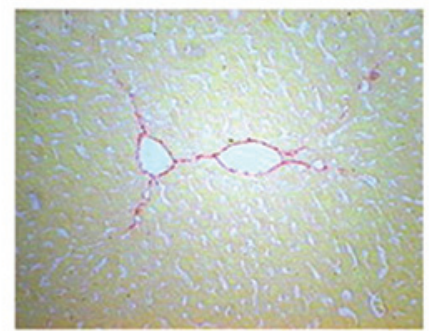

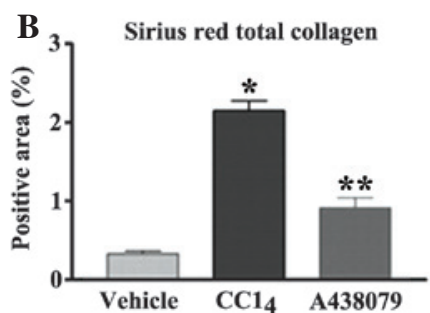

D Sirius red central vein

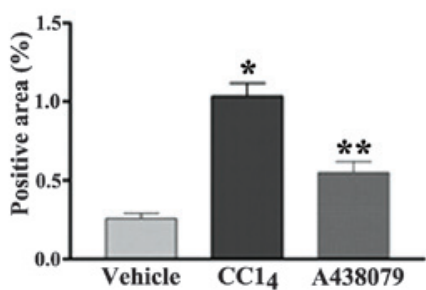

F Sirius red perihepatic collagen

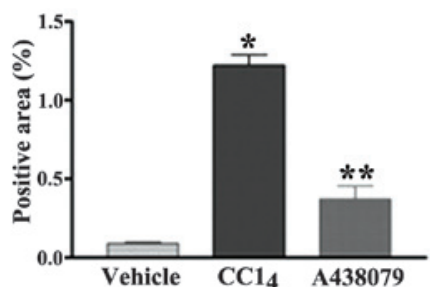

Figure 3. Sirius Red staining of (A) vehicle-treated normal control, (C) carbon tetrachloride $\left(\mathrm{CCl}_{4}\right)$-treated and $(\mathrm{E}) \mathrm{CCl}_{4}+\mathrm{A} 438079$-treated groups. $\mathrm{A}$ thin lining of collagen was observed along the central vein. In the $\mathrm{CCl}_{4}$-treated group, there was an increase in the collagen accumulation along the central vein and collagen was observed in the pericellular area. A438079 treatment reduced $\mathrm{CCl}_{4}$-induced collagen accumulation. Histograms show the percentage area of Sirius Red staining of collagen in (B) the whole liver section, (D) along the central vein and (F) the pericellular area. $\mathrm{CCl}_{4}$ treatment increased collagen deposition in the central vein and pericellular area. A438079 significantly reduced collagen formation and accumulation induced by chronic $\mathrm{CCl}_{4}$ treatment. ${ }^{*} \mathrm{P}<0.01$, vs. the vehicle-treated normal control and ${ }^{* *} \mathrm{P}<0.01$ compared with the $\mathrm{CCl}_{4}$-treated group ( $\mathrm{n}=10-12$ per group). 
A

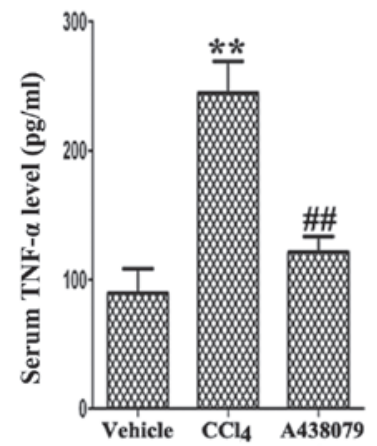

B

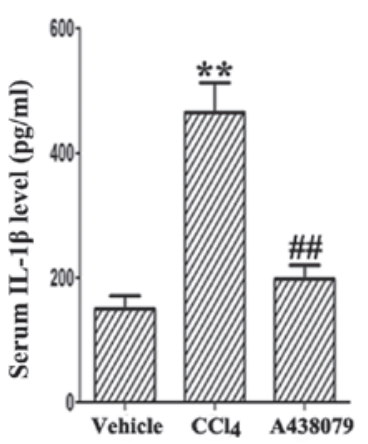

C

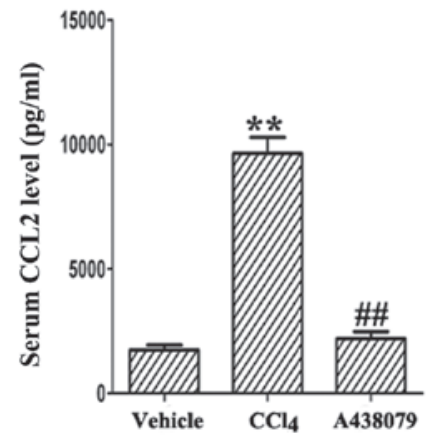

Figure 4. A438079 treatment reduced the production of serum (A) tumor necrosis factor- $\alpha($ TNF- $\alpha),(B)$ interleukin-1 $\beta$ (IL-1 $\beta$ ) and (C) CCL2. Chronic carbon tetrachloride $\left(\mathrm{CCl}_{4}\right)$ treatment significantly induced the production of TNF- $\alpha$, IL-1 $\beta$ and CCL 2 in the sera, which were all reduced by A438079 treatment. Values are expressed as the mean $\pm \mathrm{SD}, \mathrm{n}=12$ mice per group. ${ }^{* * *} \mathrm{P}<0.01$, compared with the vehicle-treated normal control and ${ }^{\# \#} \mathrm{P}<0.01$, compared with the carbon tetrachloride $\left(\mathrm{CCl}_{4}\right)$-treated group. $(\mathrm{n}=10-12$ per group).

analyzed. As expected, livers from $\mathrm{CCl}_{4}$-treated mice exhibited increased mRNA and protein levels of P2X7 compared with vehicle-treated normal mice (Fig. 1).

A438079 reduces $\mathrm{CCl}_{4}$-induced necrosis, inflammatory infiltration and cell injury. It was identified that $\mathrm{CCl}_{4}$ treatment was found to induce the formation of necrosis in the liver with inflammatory infiltration surrounding the centrilobular veins (Fig. 2B). The A438079 treatment significantly attenuated the severity of necrosis (Fig. 2C). $\mathrm{CCl}_{4}$ also increased the level of serum alanine aminotransferase (ALT), indicative of cellular injury compared with the normal control group $(\mathrm{P}<0.01)$ (Fig. 2D). Mice treated with $\mathrm{A} 438079$ and $\mathrm{CCl}_{4}$ showed a significant reduction in serum ALT and histopathological damage compared with the $\mathrm{CCl}_{4}$-treated group $(\mathrm{P}<0.01)$.
A

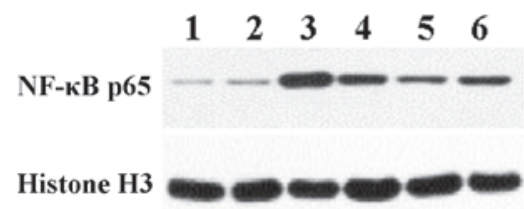

B

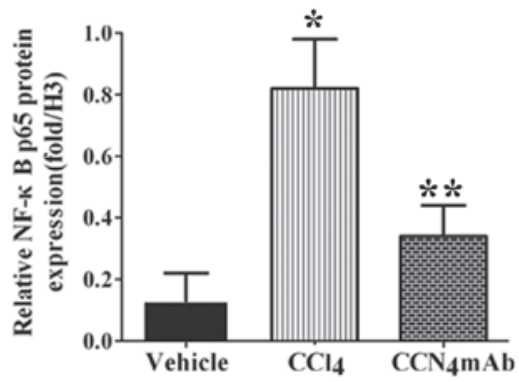

Figure 5. Nuclear factor- $\kappa \mathrm{B}(\mathrm{NF}-\kappa \mathrm{B})$ activity shown by western blot analysis (A) NF- $\kappa$ Bp65 protein expression in vehicle-treated (lanes 1 and 2), carbon tetrachloride $\left(\mathrm{CCl}_{4}\right)$-treated (lanes 3 and 4) and A438079-treated (lanes 5 and 6) mice. (B) Relative $\mathrm{NF}-\kappa \mathrm{B}$ p65 protein expression relative to internal control Histone $\mathrm{H} 3$. ${ }^{*} \mathrm{P}<0.01$ vs. vehicle-treated group and ${ }^{* *} \mathrm{P}<0.01$ vs. $\mathrm{CCl}_{4}$-treated group, $\mathrm{n}=10$ per group. Bars are the mean $\pm \mathrm{SD}$.

A
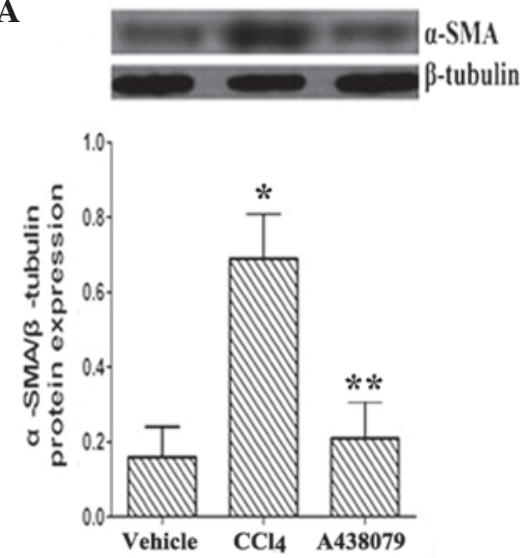

B
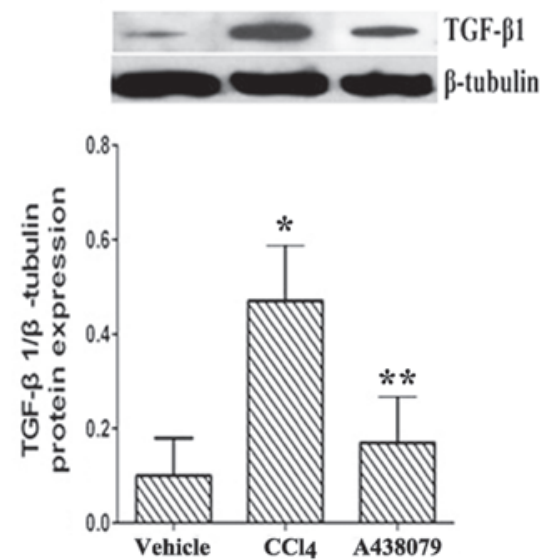

Figure 6. Protein expression levels of pro-fibrotic factors (A) $\alpha$-smooth muscle actin $\left(\alpha\right.$-SMA) and (B) tumor growth factor- $\beta 1$ TGF- $\beta 1$. Chronic $\mathrm{CCl}_{4}$ treatment upregulated the protein expression of $\alpha$-SMA and TGF- $\beta 1\left({ }^{*} \mathrm{P}<0.001\right)$. Following treatment with A438079, the expression level of $\alpha$-SMA and TGF- $\beta 1$ was significantly suppressed near to that of the control level. The protein expression levels were expressed as the ratio of band intensity for target protein relative to that for the internal control ( $\beta$-tubulin). Values are expressed as the mean $\pm \mathrm{SD}, \mathrm{n}=12$ mice per group. ${ }^{*} \mathrm{P}<0.01$, compared with the vehicle-treated normal control and ${ }^{* * *} \mathrm{P}<0.01$ compared with the $\mathrm{CCl}_{4}$-treated group. 
A438079 reduces $\mathrm{CCl}_{4}$-induced collagen accumulation in the liver. Chronic $\mathrm{CCl}_{4}$ treatment showed a significant increase in collagen accumulation in the liver (Fig. 3B). The deposition of collagen in the pericellular area and along the central vein was significantly elevated, respectively $(\mathrm{P}<0.01)$ (Fig. 3D and $\mathrm{F}$ ). Overall, the total quantity of collagen was markedly increased in the $\mathrm{CCl}_{4}$-treated mice. Treatment with $\mathrm{A} 438079$ resulted in a significant reduction of collagen accumulation within the liver compared with the $\mathrm{CCl}_{4}$-treated group $(\mathrm{P}<0.01)$.

A438079 treatment reduces the production of pro-inflammatory cytokines. Serum levels of TNF- $\alpha$, IL-1 $\beta$ and CCL2 were significantly elevated by $>4$-fold, respectively, compared with the vehicle-treated control group $(\mathrm{P}<0.01$; Fig. 4). Notably, the A438079-treated group showed markedly reduced serum levels of TNF- $\alpha$, IL-1 $\beta$ and CCL2 (all P<0.01), as indicated by ELISA. These data indicated that A438079 treatment also significantly reduced the $\mathrm{CCl}_{4}$-induced inflammatory response.

A438079 inhibits the activity of $\mathrm{NF}-\kappa \mathrm{B}$ induced by $\mathrm{CCl}_{4}$. Chronic $\mathrm{CCl}_{4}$ administration increased the activity of $\mathrm{NF}-\kappa \mathrm{B}$ to 4-fold relative to that of the normal control $(\mathrm{P}<0.01)$ (Fig. 5). The activity level of NF- $\kappa \mathrm{B}$ was significantly reduced via treatment with $\mathrm{A} 438079$, compared with that in the $\mathrm{CCl}_{4}$-treated group $(\mathrm{P}<0.01)$.

A438079 inhibits the protein expression of pro-fibrotic factors. Chronic treatment with $\mathrm{CCl}_{4}$ enhanced the protein expression levels of $\alpha$-SMA and TGF- $\beta 1$ compared with the normal control $(\mathrm{P}<0.01$; Fig. 6). A438079 treatment significantly downregulated the expression levels of these pro-fibrotic markers $(\mathrm{P}<0.01)$.

\section{Discussion}

In the present study, it was demonstrated that chronic $\mathrm{CCl}_{4}$ treatment resulted in necrosis, increased accumulation of collagen in the liver and a marked increase in the production of various pro-inflammatory and pro-fibrotic mediators, indicating the successful fibrosis model induction. Furthermore, the effects of P2X7 inhibition on liver injury and fibrosis were investigated using the specific P2X7 inhibitor, A438079. As a result, A438079 administration effectively attenuated the $\mathrm{CCl}_{4}$-induced liver injury and fibrosis.

Results of recent studies have shown that $\mathrm{P} 2 \mathrm{X} 7$ may contribute to organ fibrosis $(13,15,16)$. $\mathrm{P} 2 \mathrm{X} 7$ promotes macrophage infiltration and collagen deposition contributing to the inflammation and fibrosis of unilateral ureteral obstruction in mice (15). P2X7-deficient mice exhibited markedly reduced lung inflammation, with reduced fibrosis (13). Subsequent data demonstrated that $\mathrm{P} 2 \mathrm{X} 7$ may be a potential target for the treatment of pancreatic fibrosis (16). In accordance, the results suggested that $\mathrm{P} 2 \mathrm{X} 7$ activity was present in $\mathrm{CCl}_{4}$-induced liver injury and fibrosis and contributed to fibrogenesis.

Hepatic inflammation was correlated with liver fibrosis (17). NF- $\mathrm{NB}$ is a nuclear transcriptional activator that is central in stress responses and inflammation. Activation of $\mathrm{NF}-\kappa \mathrm{B}$ promotes the production of collagen and inflammatory chemokines in the process of liver fibrosis (18). In addition, it is indicated that monocyte infiltration into the liver is a predomi- nant pathogenic factor for chronic hepatic inflammation and fibrosis (19). In the present study, administration of A438079 reduced the $\mathrm{CCl}_{4}$-induced expression of pro-inflammatory mediators, such as TNF- $\alpha$, IL-1 $\beta$ and CCL2. In addition, A438079 reduced the activity of $\mathrm{NF}-\kappa \mathrm{B}$ during inflammation. These data demonstrated the pro-inflammatory effect of P2X7. It is suggested that the anti-inflammatory effect of A438079 may in part be regulated by NF- $\kappa \mathrm{B}, \mathrm{TNF}-\alpha$, IL- $1 \beta$ and CCL2, which are involved in the inflammatory process.

TGF- $\beta 1$ is a well-established fibrogenic cytokine, predominantly produced by $\alpha$-SMA-positive myofibroblasts (20). It is now known that subsequent to binding to its receptors, TGF- $\beta 1$ activates its downstream signaling pathway to mediate fibrosis, which is negatively regulated via the ubiquitin-proteasome degradation mechanism (21). Studies of liver biopsy samples have shown that $\alpha$-SMA may be a valuable marker in the evaluation of fibrosis progression and an early indicator of the development of fibrosis (22). In the present study, it was demonstrated that the $\mathrm{CCl}_{4}$-induced increase in the expression levels of TGF- $\beta 1$ and $\alpha$-SMA was reduced by A438079. Thus, it is suggested that the protective effect of A438079 is a result of decreased activation of various pro-fibrotic factors and the accumulation of collagen.

The results offer novel insights into the potential importance of P2X7 in hepatic fibrosis. It was demonstrated that P2X7 was upregulated in the injured livers. Furthermore, P2X7 blockade via A438079 exhibits protective effects, attenuating $\mathrm{CCl}_{4}$-induced liver injury and fibrosis. In conclusion, the protective effect of A438079 may be due to its ability to modulate the inflammatory process. However, the precise mechanism underlying the involvement of P2X7 in liver fibrosis remains unclear and requires further investigation.

\section{References}

1. Poli G: Pathogenesis of liver fibrosis: role of oxidative stress. Mol Aspects Med 21: 49-98, 2000.

2. Brenner DA: Molecular pathogenesis of liver fibrosis. Trans Am Clin Climatol Assoc 120: 361-368, 2009.

3. Cabibbo G, Maida M, Genco C, Antonucci M and Cammà C: Causes of and prevention strategies for hepatocellular carcinoma. Semin Oncol 39: 374-383, 2012.

4. Rosenbloom J, Castro SV and Jimenez SA: Narrative review: fibrotic diseases: cellular and molecular mechanisms and novel therapies. Ann Intern Med 152: 159-166, 2010.

5. Surprenant A, Rassendren F, Kawashima E, North RA and Buell G: The cytolytic P2Z receptor for extracellular ATP identified as a P2X receptor (P2X7). Science 272: 735-738, 1996.

6. Di Virgilio F, Chiozzi P, Ferrari D, et al: Nucleotide receptors: an emerging family of regulatory molecules in blood cells. Blood 97: 587-600, 2001.

7. Coutinho-Silva R, Persechini PM, Bisaggio RC, et al: $\mathrm{P} 2 \mathrm{Z} / \mathrm{P} 2 \mathrm{X} 7$ receptor-dependent apoptosis of dendritic cells. Am J Physiol 276: C1139-C1147, 1999.

8. Pelegrin P: Targeting interleukin-1 signaling in chronic inflammation: focus on P2X(7) receptor and Pannexin-1. Drug News Perspect 21: 424-433, 2008.

9. Colomar A, Marty V, Médina C, et al: Maturation and release of interleukin-lbeta by lipopolysaccharide-primed mouse Schwann cells require the stimulation of P2X7 receptors. J Biol Chem 278: 30732-30740, 2003.

10. Derks R and Beaman K: Regeneration and tolerance factor modulates the effect of adenosine triphosphate-induced interleukin 1 beta secretion in human macrophages. Hum Immunol 65: 676-682, 2004.

11. Labasi JM, Petrushova N, Donovan C, et al: Absence of the P2X7 receptor alters leukocyte function and attenuates an inflammatory response. J Immunol 168: 6436-6445, 2002. 
12. Chessell IP, Hatcher JP, Bountra C, et al: Disruption of the P2X7 purinoceptor gene abolishes chronic inflammatory and neuropathic pain. Pain 114: 386-396, 2005.

13. Riteau N, Gasse P, Fauconnier L, et al: Extracellular ATP is a danger signal activating $\mathrm{P} 2 \mathrm{X} 7$ receptor in lung inflammation and fibrosis. Am J Respir Crit Care Med 182: 774-783, 2010.

14. Díaz-Hernández M, Díez-Zaera M, Sánchez-Nogueiro J, et al: Altered P2X7-receptor level and function in mouse models of Huntington's disease and therapeutic efficacy of antagonist administration. FASEB J 23: 1893-1906, 2009.

15. Gonçalves RG, Gabrich L, Rosário A Jr, et al: The role of purinergic $\mathrm{P} 2 \mathrm{X} 7$ receptors in the inflammation and fibrosis of unilateral ureteral obstruction in mice. Kidney Int 70: 1599-1606, 2006.

16. Haanes KA, Schwab A and Novak I: The P2X7 receptor supports both life and death in fibrogenic pancreatic stellate cells. PLoS One 7: e51164, 2012.

17. Zimmermann HW, Seidler S, Nattermann J, et al: Functional contribution of elevated circulating and hepatic non-classical CD14CD16 monocytes to inflammation and human liver fibrosis. PLoS One 5: e11049, 2010.
18. Yang H, Zhao LF, Zhao ZF, et al: Heme oxygenase-1 prevents liver fibrosis in rats by regulating the expression of PPAR $\gamma$ and NF- $\kappa$ B. World J Gastroenterol 18: 1680-1688, 2010.

19. Wasmuth HE, Tacke $F$ and Trautwein C: Chemokines in liver inflammation and fibrosis. Semin Liver Dis 30: 215-225, 2010.

20. Ueberham E, Löw R, Ueberham U, et al: Conditional tetracycline-regulated expression of TGF-beta1 in liver of transgenic mice leads to reversible intermediary fibrosis. Hepatology 37 : 1067-1078, 2003

21. Derynck R and Zhang YE: Smad-dependent and Smad-independent pathways in TGF-beta family signalling. Nature 425: 577-584, 2003.

22. Akpolat N, Yahsi S, Godekmerdan A, Yalniz M and Demirbag K: The value of alpha-SMA in the evaluation of hepatic fibrosis severity in hepatitis B infection and cirrhosis development: a histopathological and immunohistochemical study. Histopathology 47: 276-280, 2005. 